\title{
Use of plate growth measurement for the estimation of skeletal growth of two sand dollars, Astriclypeus manni (Verrill 1867) and Clypeaster japonicus (Döderlein 1885), in Jeju, Korea
}

\author{
Do-Hyung Kang ${ }^{2}$, Hyun-Sung Yang ${ }^{1}$, Heung-Sik PARK $^{2} \&$ Kwang-Sik Choi ${ }^{1 *}$ \\ ${ }^{1}$ School of Applied Marine Science, College of Ocean Science, Cheju National University, 1 Ara 1-Dong, Jeju 690-756, Republic \\ of Korea \\ ${ }^{2}$ Marine Ecosystem and Conservation Research Division, Korea Ocean Research \& Development Institute, Ansan Republic of \\ Korea
}

Received 25 November 2006; Accepted 13 January 2007

\begin{abstract}
The skeletal growth patterns of two irregular sea urchins, Astriclypeus manni (Verrill 1867) and Clypeaster japonicus (Döderlein 1885), widely distributed in the shallow coastal Jeju Island, were investigated in this study. After charring by flame and subsequent clearing with xylene, a series of light and dark bands appeared on the plates consisting oral and aboral tests of both species. A strong correlation was observed between the number of dark bands and the size of $A$. manni as a test diameter (TD, $\left.\mathrm{r}^{2}=0.921\right)$; as the number of dark band increased, TD increased logarithmically. From digitized image of the plate, the radius and area of each dark band was measured using an image analyzing software. The size of sand dollar was also positively correlated with radius of the plate $\left(\mathrm{r}^{2}=0.886\right.$ for A. manni and $\mathrm{r}^{2}=0.422$ for $C$. japonicus) or area of the plate (PA, $\mathrm{r}^{2}=0.904$ for $A$. manni and $\mathrm{r}^{2}=0.704$ for $C$. japonicus). As the correlation coefficient indicated, PA was found to be a better estimation for the skeletal growth of the sand dollars. The proportion of each dark band area in a plate increased dramatically from the first band to the second and third band then it dropped gradually as the number of dark band increased. After the 7 or 8 th bands, the area or radius could no longer be measured since the distance between the two adjacent bands become too close. It was believed that the alteration of dark and light bands appeared on the plate represents the annual or seasonal growth ring, as was reported from other sea urchins and the skeletal growth of the two sand dollars are possibly age-dependent.
\end{abstract}

Key words: Astriclypeus manni, Clypeaster japonicus, skeletal growth, sand dollar

\section{Introduction}

The irregular sea urchins (sand dollars) Astriclypeus manni and Clypeaster japonicus are widely distributed on subtidal sand flats along the coastal Jeju Island in Korea. They are deposit feeders and play an important role in reworking the sediments and regeneration of nutrients in the substrate through feeding activity (Jumars et al. 1982, Telford \& Mooi 1996, Kang et al. 1999, Kang \& Choi 2002). Despite their abundance, limited information is so far available on aspects of their life histories such as population dynamics and reproduction (Tominaga 1998, Kang et al. 1999). In particular, information on age structure and skeletal growth of the sand dollars is so far, unavailable.

\footnotetext{
${ }^{1 *}$ Corresponding author: Kwang-Sik Choi; E-mail, skchoi@cheju.ac.kr
}

A number of studies have reported that the skeletal growth of echinoids is governed externally by environmental factors such as water temperature and food availability (Pearse \& Pearse 1975, Duineveld \& Jenness 1984, Ebert \& Russell 1988, 1992, Gage 1991), and internally by physiological changes including metabolism and reproduction (Gage \& Tyler 1985, Sano et al. 2001). Such influences are often well preserved in the calcitic skeletal plates of irregular as well as regular echinoids (Jensen 1969, Birkeland \& Chia 1971, Pearse \& Pearse 1975, Brykov \& Parasyna 1978, Yoo et al. 1982, Gage 1991, Chen \& Chao 1997, Hong \& Chung 1998). Annual growth bands, so-called "age-markers" are often formed on the skeletal plates comprising the oral and aboral test of echinoids (Serafy 1978, Gage 1991). In echinoids, oral and aboral tests are composed of many small plates and skeletal growth is achieved 
through increases in plate size (Pearse \& Pearse 1975, Seilacher 1979). Seasonal changes in plate growth often result in alternation of light and dark bands on the plate owing to the differing growth rates between warm and cold seasons (Brykov \& Parasyna 1978, Gage 1990, 1991). According to Pearse \& Pearse (1975) and Gage (1991), the dark or opaque bands (slow growth) form in winter, while light or translucent bands (fast growth) form in summer when water temperatures are warmer. Consequently, the plate banding patterns have been used in studies of age determination of regular as well as irregular sea urchins (Brykov \& Parasyna 1978, Gage 1991, Sano et al. 2001).

The present study reports a computer-based image analysis technique used in the measurement of skeletal growth of sand dollar, A. manni and C. japonicus in Jeju, Korea and its ecological implications.

\section{Materials and Methods}

Astriclypeus manni and Clypeaster japonicus were collected from Hamdock and Kangjung on the coast of Jeju Island (Fig. 1) in September 1999 and in June 2000 using SCUBA and trawling. A total number of 28 C. japonicus and $53 \mathrm{~A}$. manni were used in the analysis. The TD of $C$. japonicus used in this study ranged from $85.3-115.4 \mathrm{~mm}$ while the TD of $A$. manni ranged from $36.3-153.8 \mathrm{~mm}$.

To identify skeletal growth markers, the biggest plate of the oral or aboral test was selected for analysis (Fig. 2). The tests were bleached and polished with sandpaper according to Brykov \& Parasyna (1978) to contrast the growth zones.

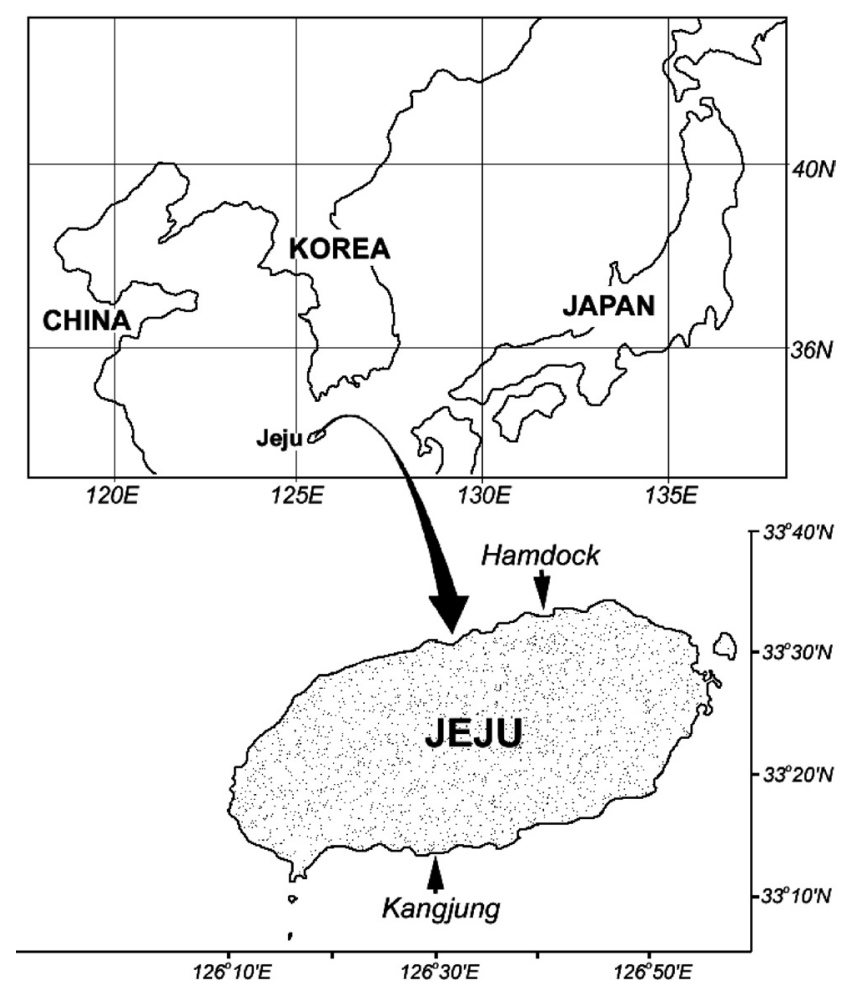

Fig. 1. Location of the sampling sites.
The polished tests were then charred over an alcohol lamp and cleaned in xylene to further contrast the appearance of the light and dark bands on the plate. The banding pattern appeared on the plates was then scanned into a personal computer using a scanner for planimetric measurement. From the digitized images, the area of each band as well as the number of light and dark bands in each plate was measured using image-analyzing software. The radius and area
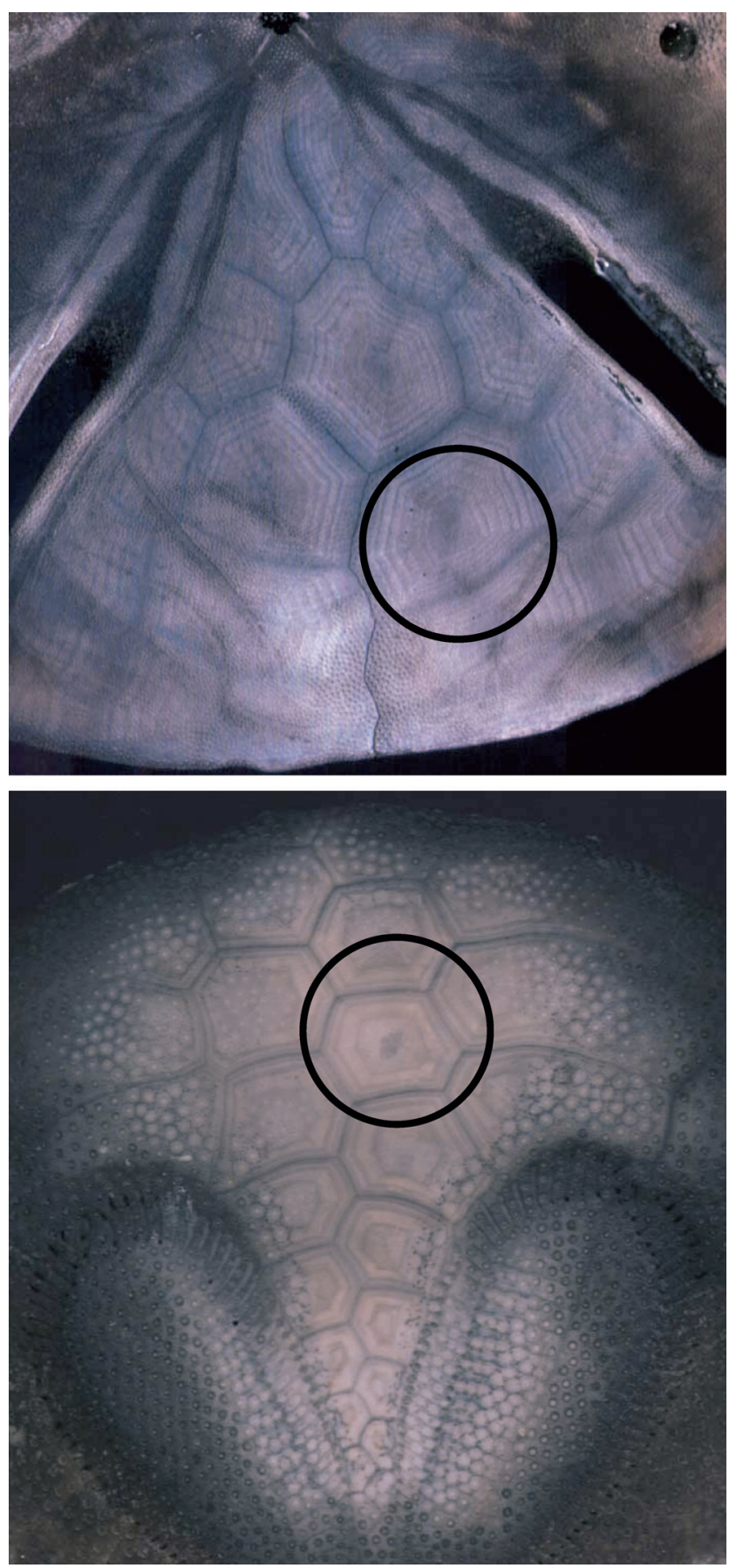

Fig. 2. Annual growth bands on the ambulacral and interambulacral plates of the oral (upper: Astriclypeus manni) and aboral (lower: Clypeaster japonicus) test. 
of each dark band, which appeared as a "series" on a plate, was measured using an image analyzer (Image-Pro ${ }^{\circledR}$, Fig. 3A). Skeletal growth pattern of the two sand dollars was then evaluated by measuring the ratio of the area between two separate dark bands, and expressing this as a percentage increment of plate area $\left(\mathrm{PIPA}, \mathrm{PIPA}=\left(\mathrm{BA}_{i+1}-\mathrm{BA}_{i}\right) \times\right.$ $100 / \mathrm{BA}_{\text {last }}, \mathrm{BA}$ is band area, $\mathrm{BA}_{i}$ is the area in $i$ th- band).

\section{Results}

\section{Identification of the growth bands}

After cleaning, the series of light and dark bands on the plates was clearly visible in both species under reflected light (Fig. 2). The light bands were wider than the dark bands in both species, indicating that the light bands were formed during periods of faster growth while the dark bands were formed in periods of slow growth. Greater overlap of the growth bands of Astriclypeus manni occurred

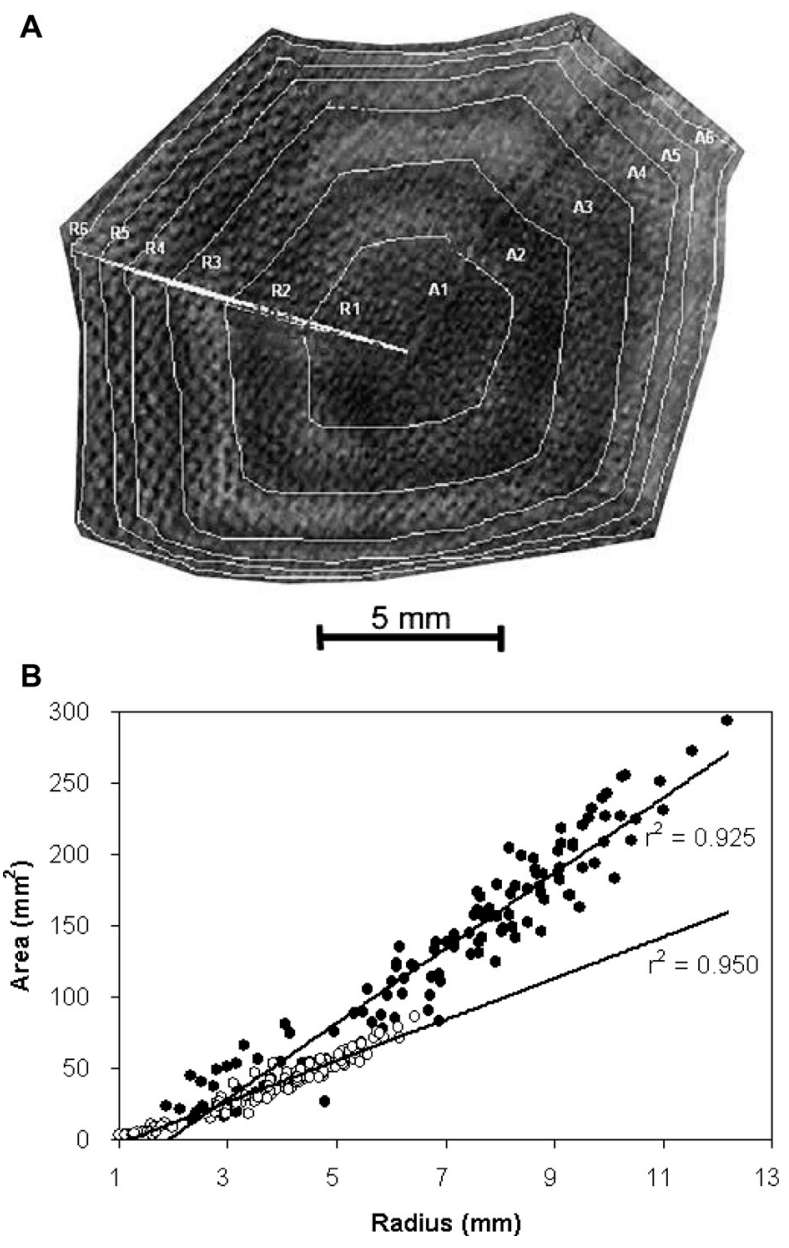

Fig. 3. A: Example plate of Astriclypeus manni (130.4 mm TD) used for calculation of PIPA with the image analyzer. $\mathrm{A}_{\text {number: }}$ : The rhombic band area in a (number) year old animal; $R_{\text {number }}$ : The radius of the plate in a (number) year old animal. B: Relationships between radius (R) and area (AR) for each age band. Solid circles: A. manni, $\mathrm{AR}=26.35 \times \mathrm{R}-50.092$; open circles: Clypeaster japonicus, $\mathrm{AR}=14.475 \times \mathrm{R}-17.146$. from the eighth band onwards, while in Clypeaster japonicus the overlap was seen to occur from the sixth band when plates were viewed under a light microscope. As the number of the bands in a plate increased, the distance between the light and dark bands became too close to be clearly distinguishable. A positive correlation was observed between the radius and area of the plate (Fig. 3B), suggesting that plate area can be a useful growth marker for assessing skeletal growth in these two species.

\section{Skeletal growth pattern}

The numbers of identified dark bands and the size of the individuals are plotted in Fig. 4. The minimum and maximum size of $C$. japonicus used in the analysis was 85.3 and $115.4 \mathrm{~mm}$ TD, respectively. These individual sand dollars exhibited four and six dark bands or growth markers on the plates respectively. Due to the lack of young individuals in the analysis, a weak correlation was observed between the size and the number of dark band $\left(\mathrm{r}^{2}=0.053\right.$, Fig. $\left.4 \mathrm{~A}\right)$. In contrast, a strong correlation between the size and the growth marker was observed from A. manni $\left(\mathrm{r}^{2}=0.921\right.$, Fig. $4 \mathrm{~B})$. The regression curve was log-linear, indicating that skeletal growth is rather size- or possibly age dependent; in-
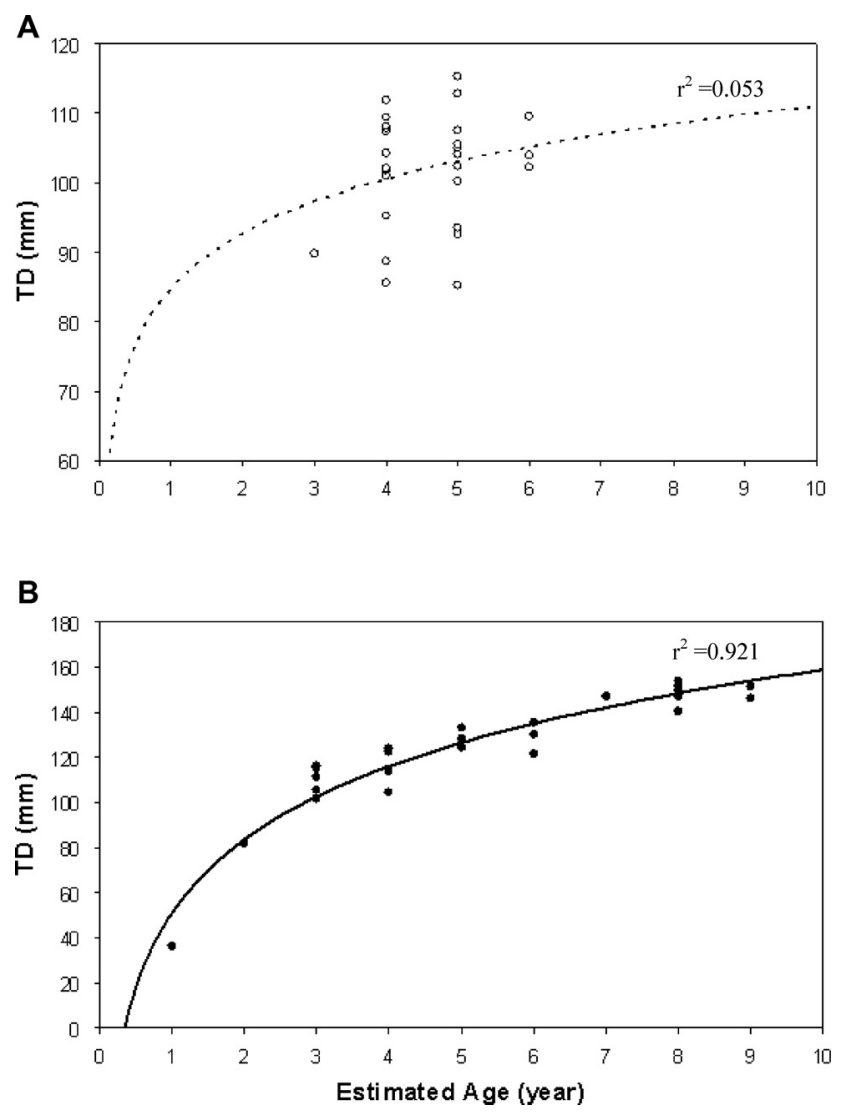

Fig. 4. Relationship between the number of dark band (or possibly age of the sand dollars) and TD of the two sand dollars. A: Clypeaster japonicus, $\mathrm{TD}=11.435 \times \mathrm{Ln}(\mathrm{EA})+84.734$. B: Astriclypeus manni, $\mathrm{TD}=46.659 \times \mathrm{Ln}(\mathrm{EA})+51.395$. 

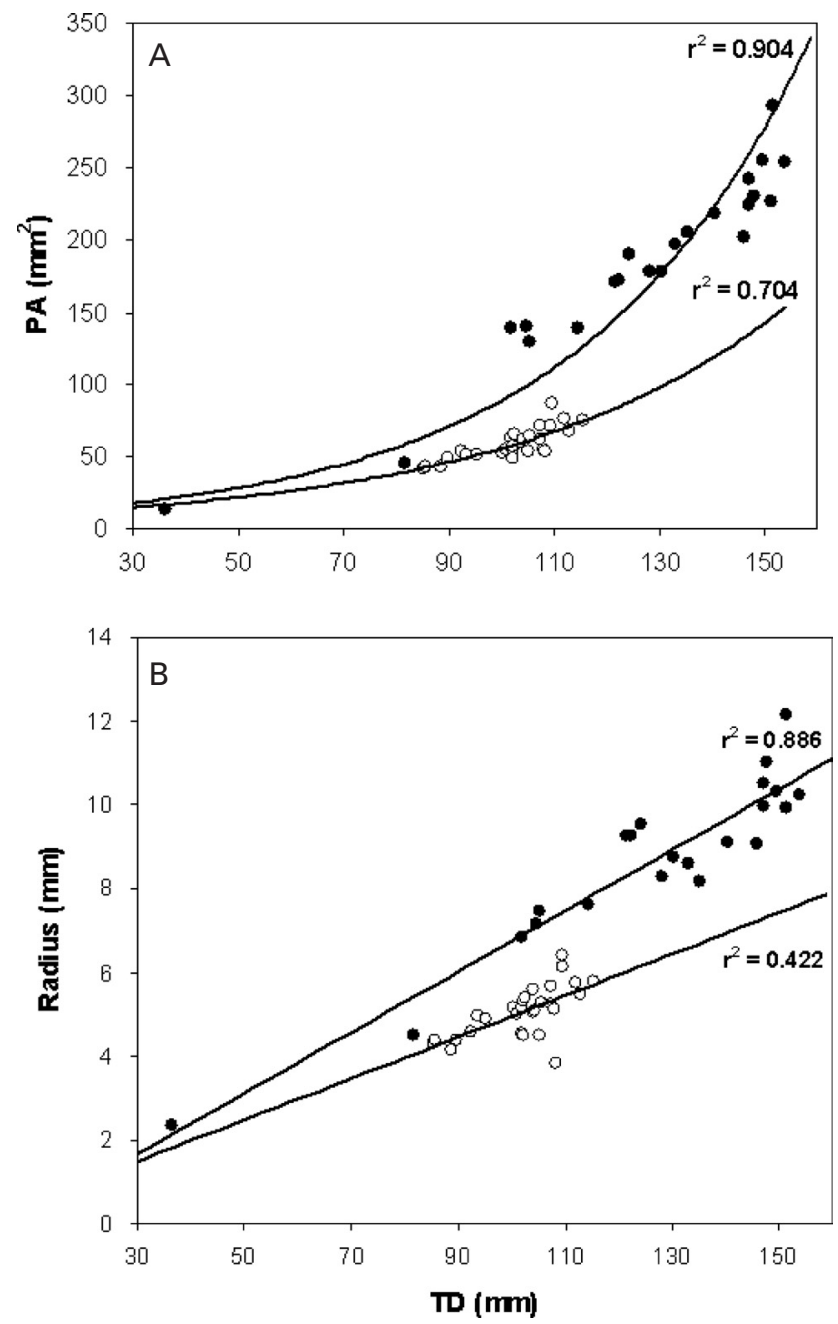

Fig. 5. Comparison of plate area (PA) and radius (R) with $\mathrm{TD}$ of the two sand dollars. Solid circle: Astriclypeus manni. Open circle: Clypeaster japonicus. A: solid circles, $\mathrm{PA}=9.0071 \times \mathrm{e}^{0.0229 \mathrm{TD}}$ $(\mathrm{n}=22, p<0.01)$; open circles, $\mathrm{PA}=8.4144 \times \mathrm{e}^{0.0189 \mathrm{TD}}(\mathrm{n}=28, p<$ 0.01). B: solid circles, $\mathrm{R}=0.0726 \times \mathrm{TD}-0.5098(\mathrm{n}=22, p<0.01)$; open circles, $\mathrm{R}=0.0496 \times \mathrm{TD}+0.002(\mathrm{n}=28, p<0.01)$.

crease in TD was rapid in A. manni between the first and 4th growth markers and after the 4th growth band, the rate of increase became slow and remained unchanged.

The relationships between PA and TD, and between radius and TD, are plotted in Fig. 5. Regression analysis indicated that TD was more strongly correlated with PA $(A$. manni, $\mathrm{PA}=9.0071 \times \mathrm{e}^{0.0229 \mathrm{TD}}, \mathrm{r}^{2}=0.904 ; C$. japonicus, $\left.\mathrm{PA}=8.4144 \times \mathrm{e}^{0.0189 \mathrm{TD}}, \mathrm{r}^{2}=0.704\right)$ than with the radius $(A$. manni, radius $=0.0726 \times \mathrm{TD}-0.5098, \mathrm{r}^{2}=0.886 ; C$. japonicus, radius $=0.0496 \times \mathrm{TD}+0.002, \mathrm{r}^{2}=0.422$ ). The regression analysis suggested that skeletal growth of the two sand dollars could be inferred from area of the plate, and that this method is more sensitive and accurate than estimations derived from the radius.

PIPA is plotted against the identified growth band in Fig. 6. PIPA of $C$. japonicus and $A$. manni increased dramatically between the first and second growth marker (9.8-

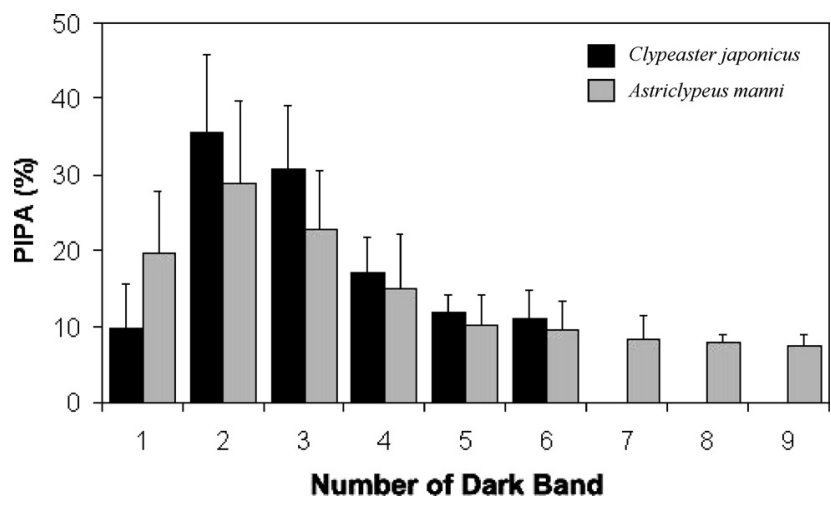

Fig. 6. Changes in PIPA with the number of dark band or possibly the age of the two sand dollars (mean \pm S.D.).

$35.5 \%)$. Between the second and sixth band, PIPA gradually decreased. These data indicate that skeletal growth is sizedependent; both sand dollars achieve $65-80 \%$ of their skeletal growth until the 4th growth marker is formed.

\section{Discussion}

The series of light and dark bands (i.e., growth marker) formed on a plate became apparent after heating, which charred organic materials contained in the plates (Fig. 2). This charring technique was also reported by Brykov \& Parasyna (1978), who also identified growth markers in the sand dollar Scaphechinus mirabilis. After grinding the plate, they heated the plate with the flame of an alcohol lamp and cleared it with xylene. Growth zones or age markers were then clearly visible in $S$. mirabilis. In regular sea urchins, age is also commonly determined by microscopic examination of a thin section of charred skeletal plate mounted on a slide under transmitted light (Heatfield 1971, Yoo et al. 1982, Chung \& Natsukari 1995, Gebauer \& Moreno 1995, Hong \& Chung 1998, Sellem et al. 2000, Sano et al. 2001). From this section a series of light and dark bands can be identified under reflected light, and the bands are used for age determination as well as for revealing patterns of skeletal growth (Birkeland \& Chia 1971, Pearse \& Pearse 1975, Brykov \& Parasyna 1978, Lane \& Lawrence 1982, Duineveld \& Jenness 1984). Gage (1990) estimated skeletal growth rates of a deep-sea brittle star by analyzing light and dark bands formed on vertebral arm ossicles. The number and spacing of the bands observed with a scanning electron microscope indicated that they form as a consequence of differing growth rates.

The light bands formed on the plates of Clypeaster japonicus and Astriclypeus manni were wider than the dark bands (Fig. 3). The dark bands, as an age marker, seem to form during periods of slow skeletal growth. So-called growth zones (the banding pattern) seem to form annually. The growth zones are formed through alternate accumulation of calcareous materials of different density, resulting in light and dark bands (Gage 1985, Sano et al. 2001). In the 
temperate zone periodic changes in environmental factors such as temperature and salinity, as well as physiological stress such as starvation and reproduction, produce these alternations. Water temperature at the study area ranges $14-30^{\circ} \mathrm{C}$ annually, a range typical of temperate zones. This wide temperature range could lead to seasonally differentiated growth rates, leading to formation of dark bands during winter and light bands during summer.

Physiological stress during the spawning period often retards skeletal growth. In marine bivalves, spawning stress results in cessation of shell growth, with a false annual growth band or age marker being formed on the shell surface as a result of the stress (Gage \& Tyler 1985, Sato 1995). Kang et al. (2002) reported that A. manni spawn in the summer from June to August when the water temperature reaches $20-25^{\circ} \mathrm{C}$. Spawning in the sand dollar could cause a certain level of stress, although it is not clear from the results of this study whether summer spawning activity leads to the retardation of skeletal growth and the formation of a band on the plate. For precise age determination in marine bivalves, the oxygen stable isotopic ratio of light and dark bands preserved on the shell surface has been analyzed to trace seasonal variations in water temperature (Krantz 1990, Jones \& Quitmyer 1996, Dettman et al. 1999, Khim 2001). Since the growth bands of sand dollars are also made of calcium carbonate containing oxygen, analysis of the stable isotopic ratio of oxygen in the bands would reveal the timing of dark and light band formation.

The size and frequency of the skeletal growth markers in the two sand dollars examined in this study were assessed using a computer-based planimetric technique. Planimetry has been widely used in the measurement of different dimensional variables such as length and area in various marine organisms (De Pontual et al. 1985, Morales-Alamo \& Mann 1987, Heffernan \& Walker 1989, Kang et al. 2003). In particular, computer-based planimetric techniques that analyze digitized images have proven to be prompt and objective in the processing of large quantities of image data (De Pontual et al. 1985, Lango-Reynoso et al. 2000, Kang et al. 2003). Most studies measuring the skeletal growth of sea urchins have used length parameters such as radius and TD (Duineveld \& Jenness 1984, David 1987, Freire et al. 1992, Hong \& Chung 1998, Branchard \& Feder 2000). As an alternative, we have measured areas of dark bands on the plate to estimate skeletal growth. The size of the sand dollars as measured by TD was more strongly correlated with PA than with the radius, suggesting that PA is a better parameter for estimating skeletal growth (Fig. 5). Measuring PA from a digital image using analysis software is also objective and rapid, and is considered to be the method of choice for skeletal growth studies.

The postulated growth curves of the two sand dollar species investigated in this study are typically log-curve (Fig. 4); growth at early phase (up to 4th growth band) is exponentially fast, with growth slowing or ceasing at a certain size. PIPA of $A$. manni and $C$. japonicus during the pe- riod of first band formation, or possibly the first year, was $48 \%$ and $45 \%$ respectively, while it was $\approx 10 \%$ in individuals estimated to be more than five years old (Fig. 6). Such exponential growth during the first year was also observed in a regular sea urchin, Strongylocentrotus franciscanus (Ebert \& Russell 1988). Exponential growth at early ages has also been reported in mussels (Blanchard \& Feder 2000). Rapid growth of the sand dollars at early ages could be beneficial through 1) reducing predation pressure-by rapid growth they quickly reach a size at which they become too big to be utilized by predators; and 2) increasing competitiveness with other species in terms of food acquisition. Kang \& Choi (2002) investigated the gut contents of A. manni, finding frustules of benthic diatoms, small particles of seaweed and exoskeletons of harpacticoid copepods. This indicates that $A$. manni is a typical deposit feeder, utilizing any possible food items in the substrate. Other deposit feeders (including the sand dollar Peronella japonica and the sea cucumber Stichopus japonicus) were also observed in the study area, indicating that these species may compete for common food resources with A. manni. However, the level of competition among these species is yet to be determined.

In conclusion, annual skeletal growth rates of $A$. manni and $C$. japonicus were estimated from growth bands present in their plates. Measurement of plate area was found to be better than the conventional plate radius measurement for estimating the skeletal growth rates. Skeletal growth patterns of the two sand dollars are possibly age-dependent; both species may achieve $86-93 \%$ of plate growth within the first to four years of life, with growth discontinuing after the age of five to six years.

\section{Acknowledgements}

We thank the staff of the shellfish research and aquaculture laboratory of Cheju National University for sampling and data analysis. This study was support by Cheju National University.

\section{References}

Birkeland C, Chia F (1971) Recruitment risk, growth, age and predation in two populations of sand dollar, Dendraster excentricus (Eschscholtz). J Exp Mar Biol Ecol 6: 265-278.

Blanchard A, Feder HM (2000) Shell growth of Mytilus trossulus Gould, 1850, IN port Valdez, Alaska. Veliger 43: 34-42.

Brykov VA, Parasyna AS (1978) Quantitative growth characteristics of the sand dollar Scaphechinus mirabilis. Soviet J Mar Biol 5: 262-266.

Chen CP, Chao CM (1997) Reduction of growth rate as the major process in the miniaturization of the sand dollar Sinaechinocyamus mai. Biol Bull 193: 90-96.

Chung SC, Natsukari Y (1995) Growth variation among the different populations of sea urchin, Pseudocentrotus depressus. J Korean Fish Soc 28: 421-427. 
David B (1987) Dynamics of plate growth in the deep-sea echinoid Pourtalesia miranda Agassiz: a new architectural interpretation. Bull Mar Sci 40: 29-47.

De Pontual H, Robert R, Miner P (1985) Study of bivalve larval growth using image processing. Aquacult Eng 17: 85-94.

Dettman DL, Reische AK, Lohmann KC (1999) Controls on the stable isotope composition of seasonal growth bands in aragonitic fresh-water bivalves (unionidae). Geochim Cosmochim AC 63: 1049-1057.

Duineveld GCA, Jenness MI (1984) Differences in growth rates of the sea urchin Echinocardium cordatum as estimated by the parameter $\mathrm{w}$ of the von Bertalanffy equation applied to skeletal rings. Mar Ecol Prog Ser 19: 65-72.

Ebert TA (1967) Negative growth and longevity in the purple sea urchin Stronglylocentrotus purpuratus (Stimpson). Science 157: 557-558.

Ebert TA, Russell MP (1988) Latitudinal variation in size structure of the west coast purple sea urchin: A correlation with headlands. Limnol Oceanogr 33: 286-294.

Freire CA, Santos PJP, Fontoura NF, Magalhaes RAO, Grohmann PA (1992) Growth and spatial distribution of Cassidulus mitis (Echinodermata: Echinoidea) on a sandy beach in southeastern Brazil. Mar Biol 112: 625-630.

Gage JD (1990) Skeletal growth markers in the deep-sea brittle stars Ophiura ljungmani and Ophiomusium lymani. Mar Biol 104: 427-435.

Gage JD (1991) Skeletal growth zones as age-markers in the seaurchin Psammechinus miliaris. Mar Biol 110: 217-228.

Gage JD, Tyler PA (1985) Growth and recruitment of the deep-sea urchin Echinus affinis. Mar Biol 90: 41-53.

Gebauer P, Moreno CA (1995) Experimental validation of the growth rings of Loxechinus albus (Molina, 1782) in southern Chile (Echinodermata: Echinoidea). Fish Res 21: 423-435.

Heatfield BM (1971) Growth of the calcareous skeleton during regeneration of spines of the sea urchin Strongylocentrotus purpuratus (Stimpson): a light and scanning electron microscopic study. J Morphol 134: 57-90.

Heffernan PB, Walker RL (1989) Quantitative image analysis methods for use in histological studies of bivalve reproduction. J Mollusc Stud 55: 135-137.

Hong SW, Chung SC (1998) Age and growth of sea urchin, Anthocidaria crassispina (A. Agassiz). J Korean Fish Soc 31: 302-308.

Jensen M (1969) Age determinations of echinoids. Sarsia 37: 41-44.

Jones DS, Quitmyer IR (1996) Marking time with bivalve shells: oxygen isotopes and season of annual increment formation. Palaios 11: 340-346.

Jumars PA, Self RFL, Nowell ARM (1982) Mechanics of particle selection by tentaculate deposit-feeders. J Exp Mar Biol Ecol 64: 47-70.

Kang D-H, Choi K-S (2002) Ecological studies on the sand dollar, Astriclypeus manni (VERRIL 1867)-feeding, density and locomotion. Korean J Environ Biol 20: 180-188.
Kang D-H, Ahn I-Y, Choi K-S (2003) Quantitative assessment of reproductive condition of the Antarctic clam, Laternula elliptica (KingandBroderip), using image analysis. Invertebr Reprod Dev 44: 71-78.

Kang D-H, Choi K-S, Chung S-C (1999) An ecological study on the sand dollar, Astriclypeus manni (VERRIL 1867), in Hamdock, Cheju Korea. J Korean Fish Soc 32: 345-352.

Khim B-K (2001) Stable isotope profiles of Serripes groenlandicus shells. II. Occurrence in Alaskan Coastal Water in south St. Lawrence Island, Northern Bering Sea. J Shellfish Res 20: 275-281.

Krantz DE (1990) Mollusk-isotope record of Plio-Pleistocene marine paleoclimate, U.S. Middle Atlantic Coastal Plain. Palaios 5: 317-335

Lane JM, Lawrence JM (1982) Food, feeding and absorption efficiencies of the sand dollar, Mellita quinquiesperforata (Leske). Estuar Coast Shelf Sci 14: 421-431.

Lango-Reynoso F, Chávez-Villalba J, Cochard JC, Pennec ML (2000) Oocyte size, a means to evaluate the gametogenic development of the Pacific oyster, Crassostrea gigas (Thunberg). Aquaculture 190: 183-199.

Morales-Alamo R, Mann R (1987) Anatomical features in histological sections of Crassostrea virginica (Gmelin, 1791) as an aid in measurements of gonad area for reproductive assessment. J Shellfish Res 8: 71-82.

Pearse JS, Pearse VB (1975) Growth zones in the echinoid skeleton. Am Zool 15: 731-753.

Sano M, Omori M, Taniguchi K, Seki T (2001) Age distribution of the sea urchin Strongylocentrotus nudus (A. Agassiz) in relation to algal zonation in a rocky coastal area on Oshika Peninsula, northern Japan. Fish Sci 67: 628-639.

Sato S (1995) Spawning periodicity and shell microgrowth patterns of the venerid bivalve Phacosoma japonicum (Reeve, 1850). Veliger 38: 61-72.

Seilacher A (1979) Constructional morphology of sand dollars. Paleobiol 5: 191-221.

Sellem F, Langar H, Pesando D (2000) Âge et croissance de l'oursin Paracentrotus lividus Lamarck, 1816 (EchinodermataEchinoidea) dans le golfe de Tunis (Méditerranée). Oceanol Acta 23: 607-613.

Serafy DK (1978) Age, growth, reproduction and sediment preference of the northern sand dollar Echinarachnius parma, on the middle Atlantic shelf (Echinodermata: Echinoidea). Am Zool 18: 664-664.

Telford M, Mooi R (1996) Podial particle picking in Cassidulus caribaearum (Echinodermata: Echinoidea) and the phylogeny of sea urchin feeding mechanisms. Biol Bull 191: 209-223.

Tominaga H (1998) Development of the Japanese keyhole sea urchins, Astriclypeus manni Verrill and Echinodiscus tenuissimus (L.Agassiz and Desor). P 9th Int Echinoderm Confer. pp. 849-853.

Yoo SK, Hur SB, Ryu HY (1982) Growth and spawning of the sea urchin Anthocidaria crassispina (A. Agassiz). J Korean Fish Soc 15: 345-358. 